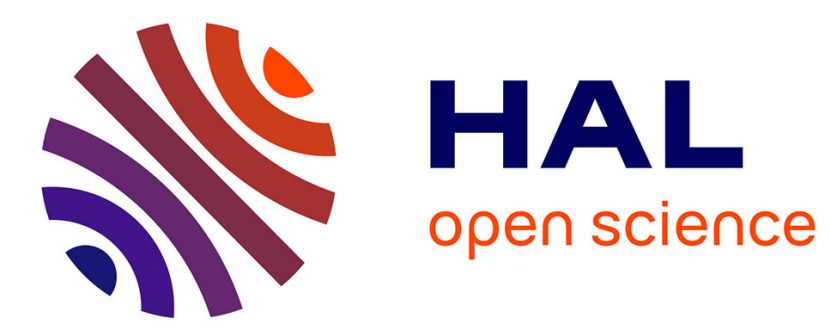

\title{
Pre-evaluation on surface profile in turning process based on cutting parameters
}

Chen Lu, Ning Ma, Zhuo Chen, Jean-Philippe Costes

\section{To cite this version:}

Chen Lu, Ning Ma, Zhuo Chen, Jean-Philippe Costes. Pre-evaluation on surface profile in turning process based on cutting parameters. International Journal of Advanced Manufacturing Technology, 2009, 49, pp.447-458. 10.1007/s00170-009-2417-9 . hal-01090941

\section{HAL Id: hal-01090941 \\ https://hal.science/hal-01090941}

Submitted on 12 Jan 2015

HAL is a multi-disciplinary open access archive for the deposit and dissemination of scientific research documents, whether they are published or not. The documents may come from teaching and research institutions in France or abroad, or from public or private research centers.
L'archive ouverte pluridisciplinaire HAL, est destinée au dépôt et à la diffusion de documents scientifiques de niveau recherche, publiés ou non, émanant des établissements d'enseignement et de recherche français ou étrangers, des laboratoires publics ou privés. 


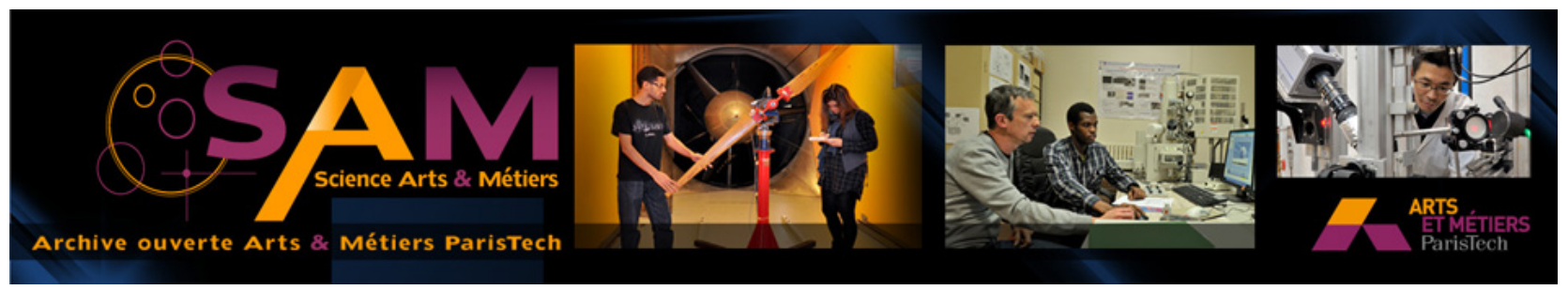

Science Arts \& Métiers (SAM)

is an open access repository that collects the work of Arts et Métiers ParisTech researchers and makes it freely available over the web where possible.

This is an author-deposited version published in: http://sam.ensam.eu

Handle ID: .http://hdl.handle.net/10985/9058

\section{To cite this version :}

Chen LU, Ning MA, Zhuo CHEN, Jean-Philippe COSTES - Pre-evaluation on surface profile in turning process based on cutting parameters - International Journal of Advanced Manufacturing Technology - Vol. 49, p.447-458 - 2009 


\title{
Pre-evaluation on surface profile in turning process based on cutting parameters
}

\author{
Chen Lu $\cdot$ Ning Ma $\cdot$ Zhuo Chen $\cdot$ Jean-Philippe Costes
}

\begin{abstract}
Traditional online or in-process surface profile (quality) evaluation (prediction) needs to integrate cutting parameters and several in-process factors (vibration, machine dynamics, tool wear, etc.) for high accuracy. However, it might result in high measuring cost and complexity, and moreover, the surface profile (quality) evaluation result can only be obtained after machining process. In this paper, an approach for surface profile preevaluation (prediction) in turning process using cutting parameters and radial basis function (RBF) neural networks is presented. The aim was to only use three cutting parameters to predict surface profile before machining process for a fast pre-evaluation on surface quality under different cutting parameters. The input parameters of RBF networks are cutting speed, depth of cut, and feed rate. The output parameters are FFT vector of surface profile as prediction (pre-evaluation) result. The RBF networks are trained with adaptive optimal training parameters related to cutting parameters and predict surface profile using the corresponding optimal network topology for each new
\end{abstract}

C. $\mathrm{Lu}(\bowtie) \cdot \mathrm{N} . \mathrm{Ma} \cdot \mathrm{Z}$. Chen

Department of System Engineering of Engineering Technology, Beihang University,

Beijing 100191, People's Republic of China

e-mail: luchen@buaa.edu.cn

N. Ma

Department of Foundation Science,

The First Aeronautical Institute of Air Force,

Xinyang 464000, People's Republic of China

J.-P. Costes

LaBoMaP, Ensam Cluny,

Rue Porte de Paris,

71250 Cluny, France cutting condition. It was found that a very good performance of surface profile prediction, in terms of agreement with experimental data, can be achieved before machining process with high accuracy, low cost, and high speed. Furthermore, a new group of training and testing data was also used to analyze the influence of tool wear on prediction accuracy.

Keywords Surface profile prediction .

Surface profile evaluation $\cdot$ Turning $\cdot$ RBF

\section{Introduction}

The surface profile of a machined part is the most important product quality characteristics. The surface finish profile of a machined workpiece is affected by cutting conditions (parameters), tool geometry, workpiece material, and other factors such as tool wear, vibrations, machine dynamics, and cooling fluid. Achieving the desired surface quality is of great importance for the functional behavior of a part. The process-dependant nature of surface profile formation mechanism along with the numerous uncontrollable factors that influence pertinent phenomena make it almost impossible to find a straightforward solution and an absolutely accurate prediction model.

Usually, if incorporating in-process factors (vibration, tool wear, machine dynamics, cooling fluid, etc.) into surface profile prediction models, the surface profile (quality) of a workpiece can only be obtained after machining process. The reason is that the above inprocess factors are actually measured (or sampled) during machining process, and even it is very difficult to accurately measure or quantify some factors for the input of neural network prediction model, such as tool wear. 
Moreover, comparing with the fact that surface profile (quality) is usually obtained after machining process, it will be more significant to predict (pre-evaluate) surface profile before machining process so that the optimal cutting parameters can be determined according to the prediction (pre-evaluation) result before machining process, avoiding the waste of machined workpiece due to unsuitable cutting parameters.

The aim of this study was to only use cutting speed $\left(v_{\mathrm{c}}\right)$, cutting depth $\left(a_{\mathrm{p}}\right)$, feed rate $(f)$ and radial basis function (RBF) neural networks to investigate the possibility of surface profile prediction (pre-evaluation) with high speed and low cost before machining process. In this study, considering the influence of tool wear, the cutting tool insert was replaced by a new insert every other several machining loop, so the cutting tool inserts were supposed not to be worn. Finally, a new group of training and testing data, composed of the above three cutting parameters along with different radius of tool nose and tool material (carbide and cermet), was also used to analyze the influence of tool wear on prediction (pre-evaluation) accuracy.

\section{Review of literature}

It is found that most research works focus on surface roughness prediction (evaluation) in machining. Due to the close relationship between profile prediction and roughness prediction in machining process, a brief review that combines them is discussed based on the work that Benardos and Vosniakos have reviewed in [1]. The classification of current literature is not easy due to the reason that many papers combine and blend different methodologies into a single approach. Therefore, no single classification would be entirely accurate. In this paper, the selected representative papers are introduced as below.

Grzesik [2] used the minimum undeformed chip thickness to predict surface roughness in turning. The study of Chang and $\mathrm{Lu}$ [3] presented a feasibility study on the prediction of surface roughness in side milling operations using the different polynomial networks and various cutting parameters. The different polynomial networks for predicting surface roughness were developed using the abduction modeling technique and based on the $F$ ratio to select their input variables. The modeling technique developed in [4] could represent the spectrum of surface topography ranging over shape, waviness, and roughness. A surface roughness, waviness, and shape error model was obtained by the Bspline curve fitting of regenerated roughness. Ehmann and Hong [5] introduced a "surface-shaping system" which modeled the machine tool kinematics and cutting tool geometry to represent the surface generation process in the simulation of 3D topography of a peripherally milled surface. Feng and Wang [6] included six parameters, namely, the hardness, feed rate, tool point angle, depth of cut, spindle speed, and cutting time, to build a model for finishing turning operations. Singh and Rao [7] investigated the effects of cutting conditions and tool geometry on surface roughness in finish hard turning. This study showed that the feed was the dominant factor determining the surface finish followed by nose radius and cutting velocity. Mathematical models for the surface roughness were developed using the response surface methodology.

Lee and Tarng [8] proposed the use of computer vision techniques to inspect surface quality. Tsai et al. [9] used machine vision to assess surface roughness of machined parts produced by shaping and milling processes. The quantitative measures of surface roughness were extracted in the spatial frequency domain using a 2D Fourier transform. Two artificial neural networks, which took roughness features as the input, were developed to determine the surface roughness. Fuchs [10] used the application of computer vision and pattern analysis for the inspection of wooden materials, such as X-ray computed tomography (CT). Faust [11] correlated camera images with stylus tracing and visual classification.

Mannan et al. [12] proposed a surface texture analysis combining sensory data from image and sound analysis to investigate the correlation between tool wear and qualitative characterizing machined surface, but it could not give a more quantitative prediction. An in-process surface roughness estimation procedure, based on least-squares support vector machines, was proposed in [13]. The cutting conditions (feed rate, cutting speed, and depth of cut), parameters of tool geometry (nose radius and nose angle), and features extracted from the vibration signals constituted the input information. In [14], the online measuring of surface roughness was estimated by taking into account the power spectrum density of friction-induced acoustic emission. Diniz et al. [15] conducted related experiments to monitor the change of surface roughness caused by the deterioration of tool wear through the variation of acoustic emission in finish turning.

Lin and Chang [16] incorporated the effect of the relative motion between cutting tool and workpiece with the effects of tool geometry and cutting parameters to simulate the surface geometry. In [17], the relative vibrations between tool and workpiece were superimposed onto the kinematic roughness calculated by tool edge radius and feed rate. It was found that the surface roughness (profile) contained specific frequency components determined by feed marks in the lower frequency range and closely related to the natural frequencies of spindle-workpiece system in the high-frequency range.

In [18], an approach for surface roughness recognition (in-process surface roughness recognition) systems to 
predict surface roughness $\left(R_{\mathrm{a}}\right)$ in-process using vibration signals and cutting conditions was introduced. The analysis of the data and the model building was carried out using a neural fuzzy system. In [19], cutting speed, feed rate, depth of cut, tool nose radius, tool overhang, approach angle, workpiece length, and workpiece diameter and vibrations in both radial and feed directions were used for evaluating tool life and surface roughness. Luo et al. [20] presented a novel approach of surface quality evaluation by online vibration analysis and feature extraction using an adaptive B-spline wavelet algorithm. The results showed that the amplitude in the selective frequency bands and the root sum square of wavelet power spectrum reflected the surface quality.

Risbood et al. [21] used cutting speed, feed rate, depth of cut, radial components of cutting force, and acceleration of radial vibration of tool holder to train different backpropagation (BP) artificial neural network (ANN) models for the prediction of surface roughness and dimensional deviation for dry and wet turning as well as for turning by high-speed steel (HSS) and carbide-coated tools. Benardos and Vosniakos [22] presented a BP ANN model trained with the Levenberg-Marquardt algorithm for the prediction of surface roughness in face milling. The considered factors were depth of cut, feed rate, cutting speed, cutting forces, the engagement and wear of cutting tool, and the use of cutting fluid. Ezugwu et al. [23] developed a three-layered BP ANN model for the analysis and prediction of the relationship between cutting conditions and process parameters. The inputs of ANN were cutting speed, feed rate, depth of cut, cutting time, and coolant pressure. The outputs were machined surface roughness, tangential force, axial force, spindle motor power, average flank wear, maximum flank wear, and nose wear. Kohli and Dixit et al. [24] proposed a neural-network-based methodology for predicting the surface roughness in a turning process by taking the acceleration of the radial vibration of the tool holder as feedback. The network model was trained using BP algorithm, and its parameters were found automatically in an adaptive manner. Mainsah and Ndumu [25] developed an online ANN-based 3D surface characterization/classification to place any new surface into its corresponding manufacturing process group and different roughness categories. Abburi and Dixit [26] developed a knowledgebased system for the prediction of surface roughness in turning using neural network and fuzzy set theory. Knowledge obtained from the experiments was used to train the neural network that provided a number of datasets. All datasets were then imported into a fuzzyset-based rule generation module to generate IF-THEN rules. Lela et al. [27] examined the influence of cutting speed, feed, and depth of cut on surface roughness in face milling. Three different modeling methodologies (regression analysis, support vector machines, and Bayesian neural network) were applied to predict surface roughness. The results obtained by the models were also compared. Regarding the influence of the examined cutting parameters on the surface roughness, the feed had the largest affect and the depth of cut the least.

Here, all factors affecting surface quality are listed as in Table 1, mostly based on the review summarized by Benardos and Vosniakos [1].

\section{Description of prediction of surface profile using RBF ANN}

As aforementioned, this work investigates the possibility to only use cutting speed $\left(v_{\mathrm{c}}\right)$, cutting depth $\left(a_{\mathrm{p}}\right)$, feed rate $(f)$, and RBF neural networks to predict (pre-evaluate) the surface profile before machining process. Comparing with many referenced works that consider the dynamic behavior of machining process and integrate in-process factors/ features (such as vibration, cutting force, tool wear, etc. measured during or after machining process) into surface quality prediction, this work hopes to find an approach for surface profile prediction (pre-evaluation) and preview using three cutting parameters before the machining process. Here, Gaussian function-based RBF ANN was employed, and cutting parameters $\left(f, a_{\mathrm{p}}, v\right)$ were used to train network for surface profile prediction the before machining process.

RBF ANNs have two operating modes, namely, training and testing. Detailed descriptions of RBF networks can be found in [28-30].The details of RBF ANN training procedure would be out of the scope of this paper. Once the centers and the widths (spreads) have been chosen, a supervised learning algorithm is applied to train the weights between the hidden and the output layer nodes. The output layer weights are usually trained using the least mean squares algorithm.

Table 1 Factors affecting surface profile and roughness

\begin{tabular}{ll}
\hline Classification & $\begin{array}{l}\text { Factors affecting surface } \\
\text { profile and roughness }\end{array}$ \\
\hline Cutting parameters & $\begin{array}{c}\text { Feed rate, cutting speed, } \\
\text { depth of cut, process kinematics } \\
\text { Tool wear, tool angle, tool } \\
\text { nose radius, tool shape, tool material, } \\
\text { runout errors, tool deflection } \\
\text { Workpiece diameter, length, hardness, } \\
\text { defect in the material, }\end{array}$ \\
Workpiece properties & $\begin{array}{l}\text { Chatter, vibrations, noise, cutting forces } \\
\text { Cooling fluid, friction in cutting } \\
\text { Machining equipment }\end{array}$ \\
Machining environment & \\
&
\end{tabular}




\section{Experimental conditions and procedure}

\subsection{Experimental setup and conditions}

Machining tests were conducted on a CNC turning lathe. Stainless steel 304L with a diameter of $95.5 \mathrm{~mm}$ was used as workpiece. The workpiece was machined using carbidecoated inserts CNMG120404-MF. Cutting conditions in the experiments are shown in Table 2. The experimental setup is shown in Fig. 1.

For generating the training data for RBF neural networks, three levels of cutting speed, feed, and depth of cut were taken (in Table 2). Thus, the entire 27 cases were combined into the training dataset of RBF ANNs; each case includes $v_{\mathrm{c}}, a_{\mathrm{p}}, f$, and the measured roughness $R_{\mathrm{a}}$ (as a reference), as shown in Table 3.

Additionally, ten cases designed randomly within and outside the range of cutting parameter levels of training dataset were employed as testing dataset (in Table 4). The testing dataset did not participate in the training process (namely, not presented to the neural networks), but it was used to test the trained ANNs and search the optimal topology among different ANN topologies.

The machining length along the workpiece for each case was taken as $10 \mathrm{~mm}$. The surface profile and roughness of the machined workpiece was measured by a SOMICRONIC SURFASCAN S-M3 and a stylus with a radius of $10 \mu \mathrm{m}$, angle $60^{\circ}$. Readings were taken three times, and the average value was recorded. The surface evaluation length in each case was taken as $5.6 \mathrm{~mm}$. Considering the influence of tool wear, the cutting tool insert was replaced by a new insert at no. 10 and no. 19 for training data and at no. 6 for testing data, respectively, so the cutting tool insert was supposed not to be worn.

\subsection{Preparation and preprocessing of training dataset using fast Fourier transform}

For the prediction of surface profile, three cutting parameters $\left(v_{\mathrm{c}}, a_{\mathrm{p}}, f\right)$ were used to compose the input matrix $(3 \times 27)$ of a RBF ANN, namely, the number of nodes in the input layer was 3. A fast Fourier transform (FFT)-based approach to define the output matrix of a RBF ANN was tried based on the work introduced by Poulachon et al. [31]. It is illustrated

Table 2 Cutting conditions

\begin{tabular}{ll}
\hline Cutting speed level $(\mathrm{m} / \mathrm{min})$ & $220,260,300$ \\
Feed rate level $(\mathrm{mm} / \mathrm{rev})$ & $0.1,0.15,0.2$ \\
Depth of cut level $(\mathrm{mm})$ & $0.3,0.8,1.3$ \\
Coolant condition & Dry turning \\
Cutting tool insert & CNMG 1204 04-MF \\
Tool holder & PCLNL 2525M12 \\
\hline
\end{tabular}

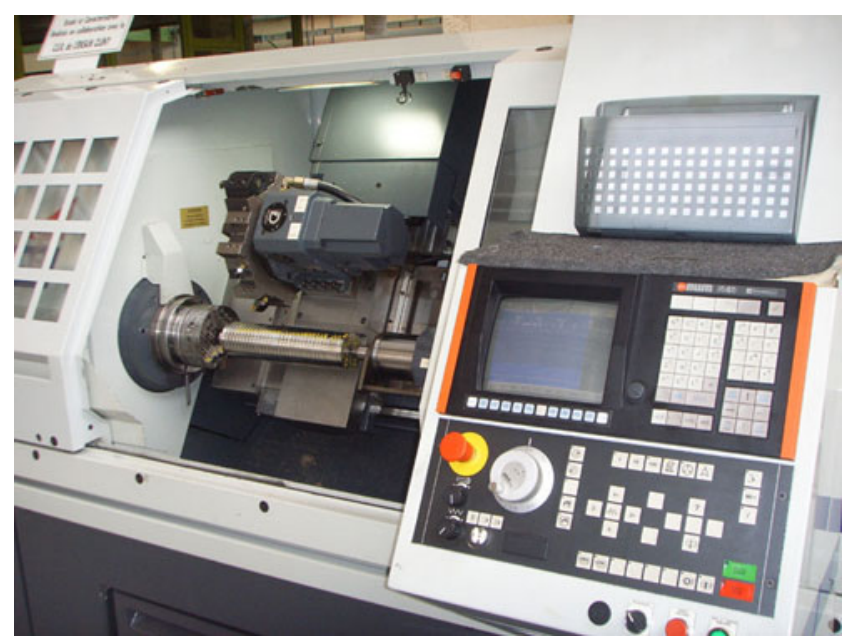

Fig. 1 Experimental setup

as following: (1) Surface profile data measured by a stylus is first performed on a 1,024-point FFT, which is actually a transform from spatial domain to spatial frequency domain. (2) Real and imaginary parts in the FFT complex vector are

Table 3 Training dataset for RBF ANN

\begin{tabular}{|c|c|c|c|c|}
\hline Case no. & $v_{\mathrm{c}}(\mathrm{m} / \mathrm{min})$ & $a_{\mathrm{p}}(\mathrm{mm})$ & $f(\mathrm{~mm} / \mathrm{rev})$ & $R_{\mathrm{a}}(\mu \mathrm{m})$ \\
\hline 1 & 220 & 0.3 & 0.1 & 0.612 \\
\hline 2 & 220 & 0.3 & 0.15 & 1.195 \\
\hline 3 & 220 & 0.3 & 0.2 & 1.606 \\
\hline 4 & 220 & 0.8 & 0.1 & 0.547 \\
\hline 5 & 220 & 0.8 & 0.15 & 1.583 \\
\hline 6 & 220 & 0.8 & 0.2 & 1.998 \\
\hline 7 & 220 & 1.3 & 0.1 & 0.563 \\
\hline 8 & 220 & 1.3 & 0.15 & 1.004 \\
\hline 9 & 220 & 1.3 & 0.2 & 1.268 \\
\hline 10 & 260 & 0.3 & 0.1 & 0.636 \\
\hline 11 & 260 & 0.3 & 0.15 & 1.183 \\
\hline 12 & 260 & 0.3 & 0.2 & 1.581 \\
\hline 13 & 260 & 0.8 & 0.1 & 0.871 \\
\hline 14 & 260 & 0.8 & 0.15 & 1.705 \\
\hline 15 & 260 & 0.8 & 0.2 & 2.160 \\
\hline 16 & 260 & 1.3 & 0.1 & 0.655 \\
\hline 17 & 260 & 1.3 & 0.15 & 1.010 \\
\hline 18 & 260 & 1.3 & 0.2 & 1.269 \\
\hline 19 & 300 & 0.3 & 0.1 & 0.634 \\
\hline 20 & 300 & 0.3 & 0.15 & 1.194 \\
\hline 21 & 300 & 0.3 & 0.2 & 1.469 \\
\hline 22 & 300 & 0.8 & 0.1 & 1.100 \\
\hline 23 & 300 & 0.8 & 0.15 & 1.645 \\
\hline 24 & 300 & 0.8 & 0.2 & 2.185 \\
\hline 25 & 300 & 1.3 & 0.1 & 0.623 \\
\hline 26 & 300 & 1.3 & 0.15 & 0.983 \\
\hline 27 & 300 & 1.3 & 0.2 & 1.327 \\
\hline
\end{tabular}


Table 4 Testing dataset for RBF ANN

\begin{tabular}{ccccc}
\hline Case no. & $v_{\mathrm{c}}(\mathrm{m} / \mathrm{min})$ & $a_{\mathrm{p}}(\mathrm{mm})$ & $f(\mathrm{~mm} / \mathrm{rev})$ & $R_{\mathrm{a}}(\mu \mathrm{m})$ \\
\hline 1 & 350 & 1.5 & 0.25 & 1.465 \\
2 & 300 & 1.2 & 0.18 & 1.411 \\
3 & 230 & 1.2 & 0.16 & 1.140 \\
4 & 230 & 1.2 & 0.2 & 1.384 \\
5 & 260 & 0.9 & 0.15 & 1.193 \\
6 & 260 & 0.8 & 0.19 & 1.688 \\
7 & 220 & 0.8 & 0.12 & 0.795 \\
8 & 220 & 0.75 & 0.12 & 0.857 \\
9 & 290 & 0.35 & 0.16 & 1.234 \\
10 & 290 & 0.3 & 0.19 & 1.490 \\
\hline
\end{tabular}

separated to construct a new $2048 \times 1$ target (output) vector in which the real part lies in the first 1,024 elements and the imaginary part in the latter 1,024 elements. (3) The above steps are repeated for each profile in the training dataset. (4) After the training of the RBF network, each testing input vector is simulated, and a $2,048 \times 1$ vector, which contains the real and imaginary parts of FFT predicted by the trained RBF network, is then obtained. (5) Perform an inverse FFT to reconstruct the output profile, which is actually a transform form spatial frequency domain to spatial domain.

Here, each 2,048 $\times 1$ FFT target (output) vector of 27 training cases, together with the corresponding $3 \times 1$ input vector, were used to train a $\mathrm{RBF}$ network for the prediction of surface profile. The training dataset was composed of $3 \times$ 27 input matrix and $2,048 \times 27$ output matrix.

Prior to training the network, the input $P$ and target (output) $T$ were normalized as $p n$ and $t n$ within the range of \pm 1 using Eqs. 1 and 2:

$p n=\frac{2 \times(P-\min P)}{(\max P-\min P)}-1$

$t n=\frac{2 \times(T-\min T)}{(\max T-\min T)}-1$

\subsection{Training of RBF neural networks}

The training and simulation were conducted using the neural network functions in Matlab [32] which include newrbe (), sim (), and mse (). The data acquired from the turning process were divided into the training dataset comprising 27 cases and the testing dataset comprising ten cases.

net $=$ newrbe $(\mathrm{P}, \mathrm{T}$, spread $)$, where, $\mathrm{P}, \mathrm{T}$, spread , and net are input vector, target vector, spread of RBF, and returned network structure, respectively. newrbe( ) very quickly designs an exact radial basis network with zero error. The larger is that spread, the smoother the function approximation will be. To fit data closely, use a spread smaller than the typical distance between input vectors. To fit the data more smoothly, use a larger spread.

Function $\mathrm{Yt}=\operatorname{sim}($ net, $\mathrm{pt})$, where, $\mathrm{pt}, \mathrm{Yt}$ are the input and simulated result of testing dataset, respectively.

The performance of a RBF network, namely, generalization ability for testing dataset outside the range of training dataset, can be evaluated using mean squared error (MSE). The smaller is the return value, the better is the generalization ability of a trained neural network.

\subsection{Searching and determination of optimal training} parameters

It has been found that a RBF network trained with different spread values always returns different performances. Figure $2 \mathrm{a}$ is the measured profile with $v_{\mathrm{c}}=260, a_{\mathrm{p}}=0.8$, $f=0.19$ which lies in the testing dataset in Table 4 . Figure $2 b$ is the surface profile predicted by a RBF network trained with spread $=0.14$, and Fig. $2 \mathrm{c}$ is the surface profile predicted by a RBF network trained with a default spread $=1$. It is shown that Fig. $2 b$ has a better correlation with the measured profile than Fig. $2 \mathrm{c}$ and that the spread parameter, which is used in the training of the RBF network, can significantly influence the trained network on the accuracy of prediction and generalization ability.

Therefore, prior to determining the final spread for the training of a RBF network, it is suggested to train the RBF network with different spreads to find the optimal spread for the testing dataset. In this study, the testing dataset (in Table 4) was used to evaluate the performance of all
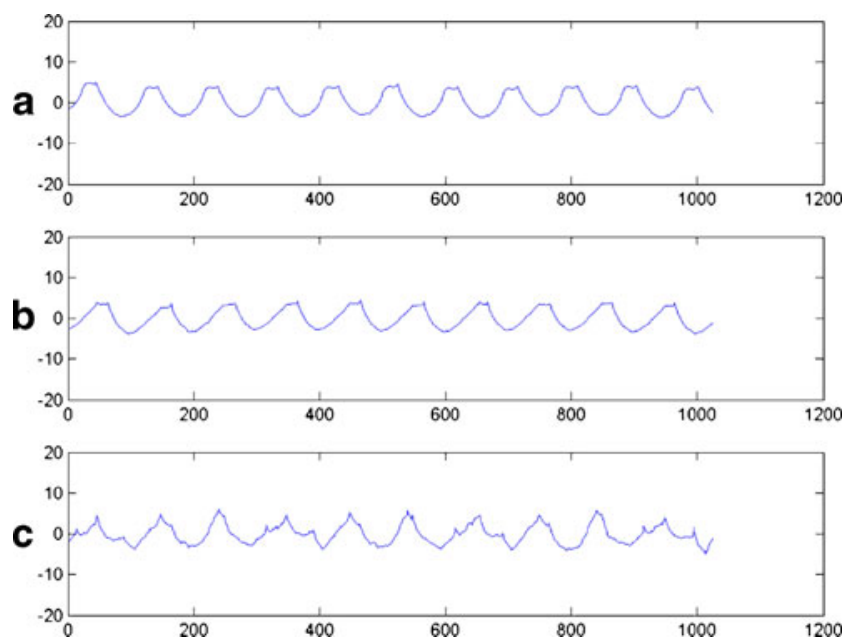

Fig. 2 Simulation of surface profile. a Measured profile. b Predicted profile, spread $=0.14$. c Predicted profile, spread $=1$ 
candidate networks trained with different spreads and find out the optimal network with the least MSE.

A total of 116 RBF network topologies were trained using the training dataset (in Table 3) and 116 different spreads ranging from 0.05 to 1.2 with a step of 0.01 , then $\operatorname{sim}()$ and $m s e()$ were employed to evaluate the prediction performance for the given testing dataset. One hundred sixteen MSE values between the predicted and measured profiles for the whole testing dataset were obtained, respectively, as shown in Fig. 3. It can be seen that the optimal spread value was 0.16 and the corresponding MSE was 4.3904, namely, when the training parameter spread was 0.16 , the trained RBF network could give the least prediction error for the whole testing dataset.

4.5 Online retraining and readjusting of RBF network using a dynamic spread

However, for the prediction of surface profile, the aforementioned spread was only a global optimal value for the whole testing dataset. It might not be a local optimal value for each case within the testing dataset. It was found that for some cases, the best correlation of profile shape and amplitude between the measured and predicted profiles were attained using the RBF network trained at a spread value near 0.16 , such as $0.15,0.135$, etc. Therefore, the determination of local optimal spread value needs a coarse-adjusting and fine-adjusting procedure, and it should take into account not only MSE performance but also the correlation degree of shape and amplitude.

It was also found that for each case in the testing dataset, the depths of cut $\left(a_{\mathrm{p}}\right)$ were significantly related to the local

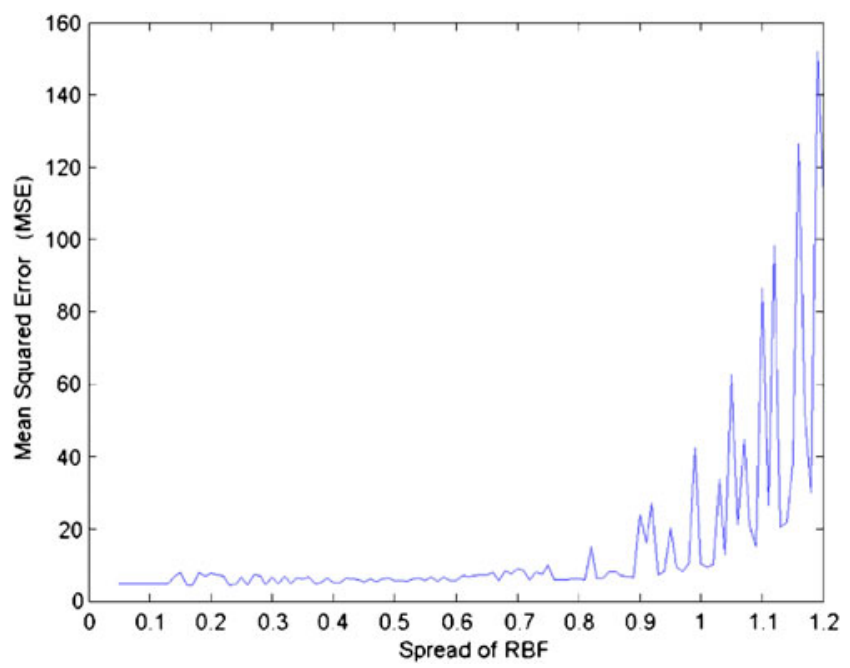

Fig. 3 Spreads versus mean squared errors (MSE) for the whole testing dataset optimal spreads. Namely, a RBF network trained with a fixed spread parameter would not guarantee the optimal prediction or best generalization ability for all profile prediction cases.

It is suggested that at each new prediction, the RBF network trained by prior optimal spread parameter should be online retrained and updated using a new optimal spread training parameter for high accuracy. The new optimal spread can be found from the correlation mapping between $a_{\mathrm{p}}$ and optimal spread values. In this experiment, under the specified machine, workpiece, cutting conditions as shown in Table 2, and the given range of the datasets in Tables 3 and 4 , the correlation mapping between $a_{\mathrm{p}}$ and optimal spreads was established for online retraining a RBF neural network, as shown in Fig. 4.

The online retraining of a RBF neural network using a dynamic spread parameter can be summarized as the following steps:

1. Suppose there is a new given case $\left(v_{\mathrm{c}}, a_{\mathrm{p}}, f\right)$ to be predicted its surface profile.

2. Select an appropriate optimal spread value according to the correlation mapping. Then, train a RBF network using the optimal spread parameter and the original training dataset.

3. Once the training goal is met, dynamically update the RBF network with the new weights and biases and then simulate (predict) the given case, obtaining the predicted surface profile.

4. The procedure is repeated for any new case. Since a RBF network designs and creates a new topology very quickly, it is very feasible to online retrain a RBF network and predict.

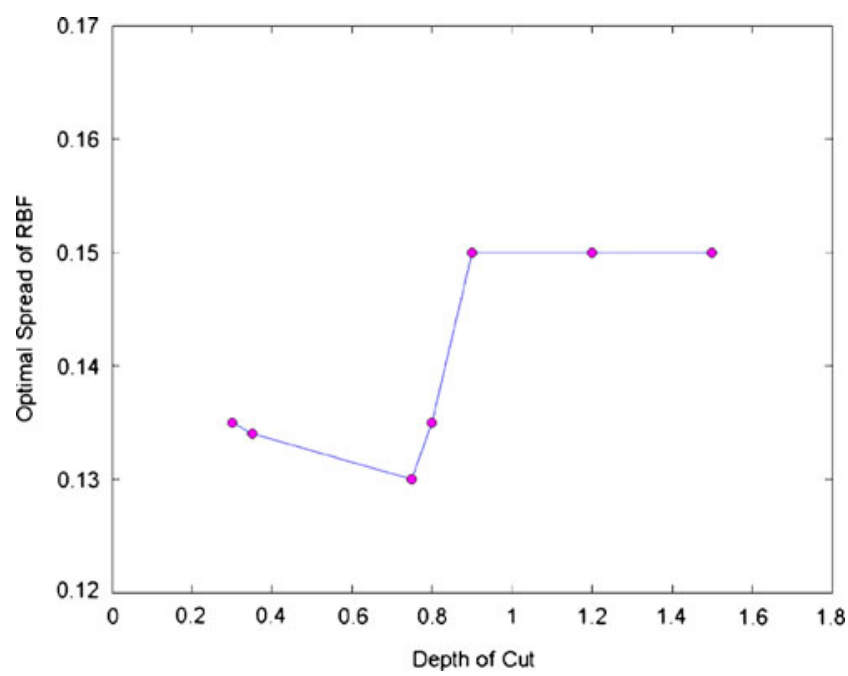

Fig. 4 Correlation between depth of cut and corresponding optimal spread 

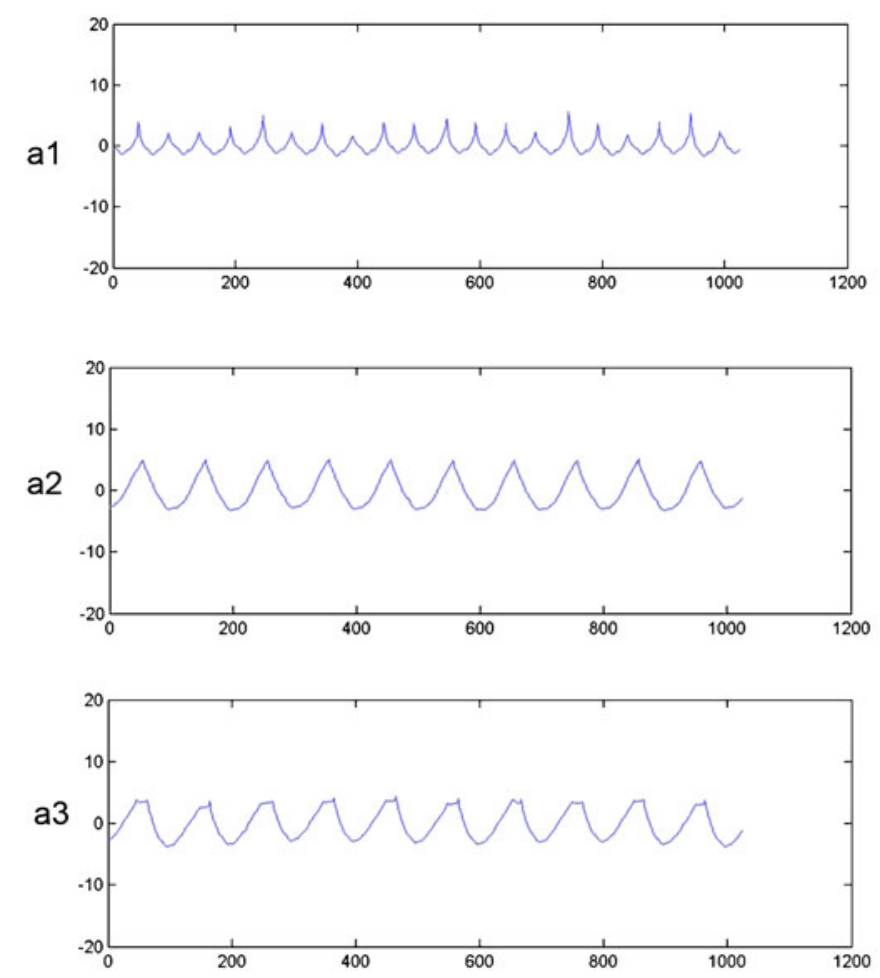

Fig. 5 Comparison between predicted profiles and measured profiles

\section{Results and discussion}

Ten cases of testing dataset were used to evaluate the RBF neural network that performed the prediction of surface profile.

\subsection{Experimental results of surface profile prediction}

Due to limit of pages, part of ten predictions of surface profiles is shown in Fig. 5. The left subfigures (a1, a2, a3) are "predicted profiles" and the right ones (b1, b2, b3) "measured profiles." The corresponding cutting condition, the MSE between the predicted profile and the measured profile, and the spread which was selected adaptively for each profile prediction are listed as below:

$(\mathrm{a} 1, \mathrm{~b} 1): v_{\mathrm{c}}=220, a_{\mathrm{p}}=0.8, f=0.12, \mathrm{MSE}=2.2616$, spread $=0.133$

$(\mathrm{a} 2, \mathrm{~b} 2): v_{\mathrm{c}}=230, a_{\mathrm{p}}=1.2, f=0.2, \mathrm{MSE}=4.3842$, spread $=$ 0.15

(a3, b3): $v_{\mathrm{c}}=260, a_{\mathrm{p}}=0.8, f=0.19, \mathrm{MSE}=17.7826$, spread $=0.14$

In each subfigure of Fig. 5, the horizontal axes denotes the 1,200 data points along the axial direction of workpiece surface, and the vertical axes is the amplitude values of surface profile.
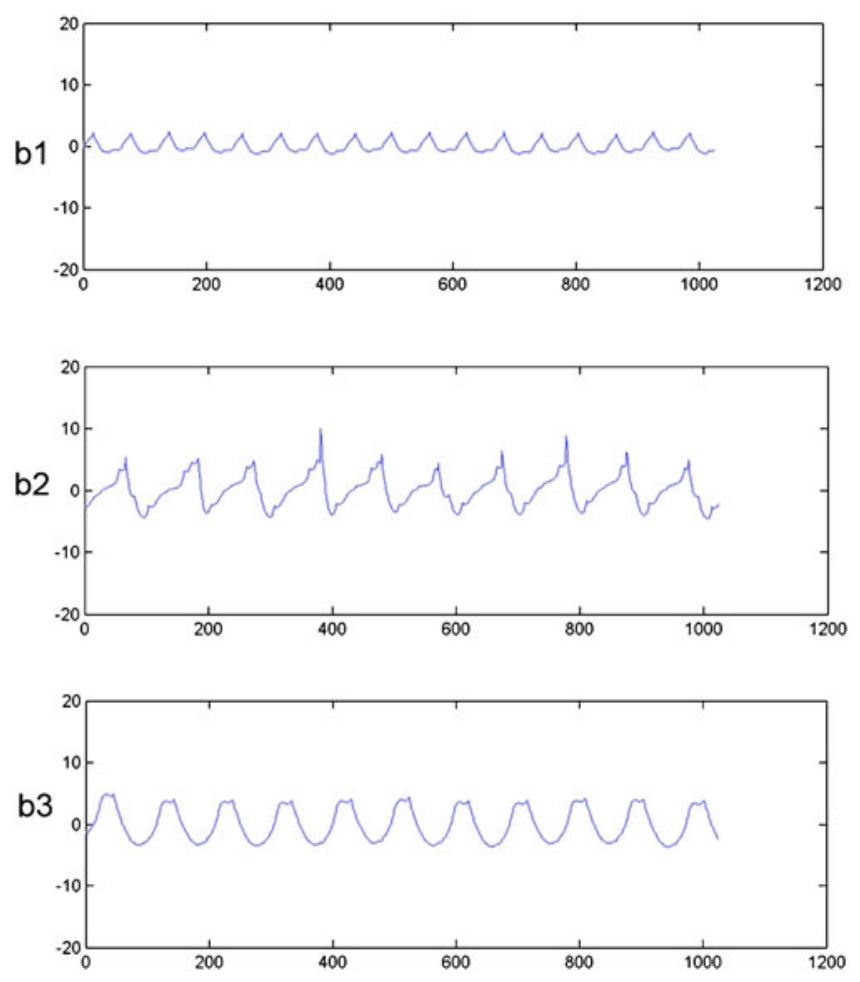

It can be seen from Fig. 5 that the predicted profiles have a good correlation with the measured profiles in terms of profile shape, trend, and amplitude range. After selecting an appropriate optimal spread value, each testing profile was predicted using the RBF neural network trained with this spread. The MSE value in each testing case might not be the least value; however, the corresponding spread is just the optimal training parameter, and the corresponding predicted profile has the best correlation with the measured actual profile than those spreads with other MSEs.

From the results, it is found that the predicted profiles are still at small variance with the measured profiles in terms of amplitude, shape, and initial phase consistency. The reason should be the presence of a lot of disturbing factors in the turning process; the factors might involve stochastic vibrations of spindle-workpiece, vibrations of

Table 5 Ranges and levels of cutting parameters for new training dataset
Cutting speed ( $\mathrm{m} / \mathrm{min})$

Feed rate $(\mathrm{mm} / \mathrm{rev})$

Depth of cut (mm)

Radius of tool nose $\left(R_{\mathrm{e}}, \mathrm{mm}\right)$

Tool material
$50,100,200,400$

$0.04,0.07,0.12,0.2$

$0.05,0.1,0.2,0.4$

$0.4,0.8$

Carbide (0), cermet (1) 
Table 6 Training dataset for RBF ANN

\begin{tabular}{|c|c|c|c|c|c|c|c|c|c|c|c|}
\hline $\begin{array}{l}\text { Case } \\
\text { no. }\end{array}$ & $\begin{array}{l}v_{\mathrm{c}} \\
(\mathrm{m} / \mathrm{min})\end{array}$ & $\begin{array}{l}a_{\mathrm{p}} \\
(\mathrm{mm})\end{array}$ & $\begin{array}{l}f \\
(\mathrm{~mm} / \mathrm{rev})\end{array}$ & $\begin{array}{l}R_{\mathrm{e}} \\
(\mathrm{mm})\end{array}$ & $\begin{array}{l}\text { Tool } \\
\text { material }\end{array}$ & $\begin{array}{l}\text { Case } \\
\text { no. }\end{array}$ & $\begin{array}{l}v_{\mathrm{c}} \\
(\mathrm{m} / \mathrm{min})\end{array}$ & $\begin{array}{l}a_{\mathrm{p}} \\
(\mathrm{mm})\end{array}$ & $\begin{array}{l}f \\
(\mathrm{~mm} / \mathrm{rev})\end{array}$ & $\begin{array}{l}R_{\mathrm{e}} \\
(\mathrm{mm})\end{array}$ & $\begin{array}{l}\text { Tool } \\
\text { material }\end{array}$ \\
\hline 1 & 50 & 0.05 & 0.04 & 0.4 & 0 & 49 & 400 & 0.1 & 0.04 & 0.4 & 0 \\
\hline 2 & 50 & 0.1 & 0.04 & 0.4 & 1 & 50 & 400 & 0.05 & 0.04 & 0.4 & 1 \\
\hline 3 & 50 & 0.05 & 0.07 & 0.8 & 0 & 51 & 400 & 0.1 & 0.07 & 0.8 & 0 \\
\hline 4 & 50 & 0.1 & 0.07 & 0.8 & 1 & 52 & 400 & 0.05 & 0.07 & 0.8 & 1 \\
\hline 5 & 50 & 0.1 & 0.2 & 0.4 & 0 & 53 & 400 & 0.05 & 0.2 & 0.4 & 0 \\
\hline 6 & 50 & 0.05 & 0.2 & 0.4 & 1 & 54 & 400 & 0.1 & 0.2 & 0.4 & 1 \\
\hline 7 & 50 & 0.1 & 0.12 & 0.8 & 0 & 55 & 400 & 0.05 & 0.12 & 0.8 & 0 \\
\hline 8 & 50 & 0.05 & 0.12 & 0.8 & 1 & 56 & 400 & 0.1 & 0.12 & 0.8 & 1 \\
\hline 9 & 50 & 0.4 & 0.07 & 0.4 & 0 & 57 & 400 & 0.2 & 0.07 & 0.4 & 0 \\
\hline 10 & 50 & 0.2 & 0.07 & 0.4 & 1 & 58 & 400 & 0.4 & 0.07 & 0.4 & 1 \\
\hline 11 & 50 & 0.4 & 0.04 & 0.8 & 0 & 59 & 400 & 0.2 & 0.04 & 0.8 & 0 \\
\hline 12 & 50 & 0.2 & 0.04 & 0.8 & 1 & 60 & 400 & 0.4 & 0.04 & 0.8 & 1 \\
\hline 13 & 50 & 0.2 & 0.12 & 0.4 & 0 & 61 & 400 & 0.4 & 0.12 & 0.4 & 0 \\
\hline 14 & 50 & 0.4 & 0.12 & 0.4 & 1 & 62 & 400 & 0.2 & 0.12 & 0.4 & 1 \\
\hline 15 & 50 & 0.2 & 0.2 & 0.8 & 0 & 63 & 400 & 0.4 & 0.2 & 0.8 & 0 \\
\hline 16 & 50 & 0.4 & 0.2 & 0.8 & 1 & 64 & 400 & 0.2 & 0.2 & 0.8 & 1 \\
\hline
\end{tabular}

Table 6 (continued)

$\begin{array}{lllll}18 & 100 & 0.1 & 0.07 & 0.4\end{array}$

lathe, vibrations of tool holder, chatter phenomena of lathe, disturbance of chip formation, etc.

It was also found that the search procedure for the optimal RBF network took a very short time length. Under a PC simulation platform of 1.6-GHz CPU with a memory size of $512 \mathrm{M}$, for RBF neural network, it took only about $7 \mathrm{~s}$ to reach the best one from 116 candidates and is very competent for the surface profile prediction that demands high-dimensional output vector (neurons).

\section{Influence of tool wear on surface profile pre-evaluation}

As aforementioned, the cutting tool was supposed not to be worn during machining process because it was replaced by a new insert once a tool wear would appear. Therefore, the approach proposed in this study is suitable for predicting (pre-evaluating) surface profile with a low prediction error

Table 7 Testing dataset for RBF ANN

\begin{tabular}{cccccc}
\hline Case no. & $\begin{array}{l}v_{\mathrm{c}} \\
(\mathrm{m} / \mathrm{min})\end{array}$ & $\begin{array}{l}a_{\mathrm{p}} \\
(\mathrm{mm})\end{array}$ & $\begin{array}{l}f \\
(\mathrm{~mm} / \mathrm{rev})\end{array}$ & $\begin{array}{l}R_{\mathrm{e}} \\
(\mathrm{mm})\end{array}$ & $\begin{array}{l}\text { Tool } \\
\text { material }\end{array}$ \\
\hline 1 & 120 & 0.45 & 0.05 & 0.4 & 0 \\
2 & 380 & 0.37 & 0.08 & 0.4 & 0 \\
3 & 180 & 0.25 & 0.1 & 0.4 & 0 \\
4 & 260 & 0.2 & 0.18 & 0.4 & 0 \\
5 & 220 & 0.12 & 0.2 & 0.4 & 0 \\
\hline
\end{tabular}



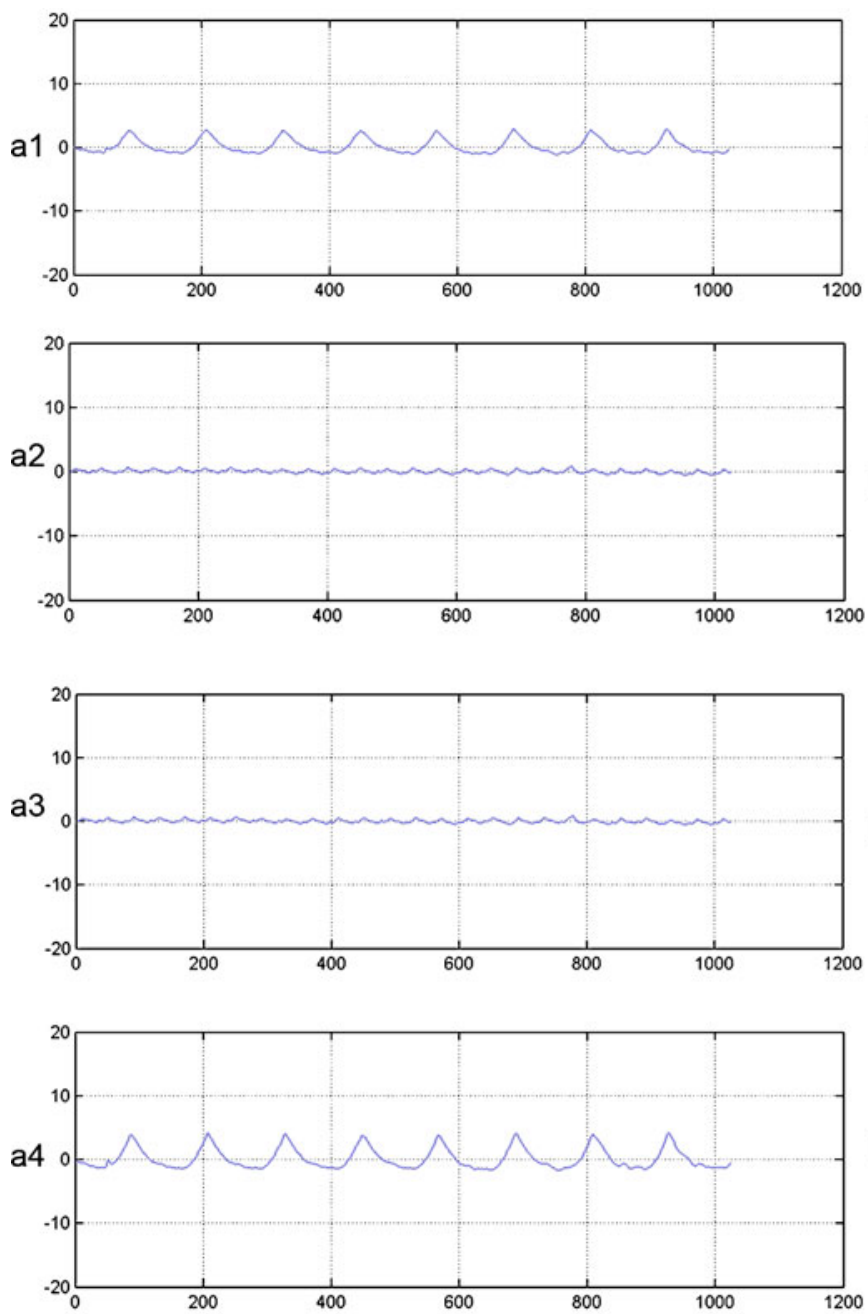

Fig. 6 Comparison between predicted profiles and measured profiles

before those turning processes in which the cutting tools are replaced by a new insert once a tool wear is forthcoming. Here, the accuracy of surface profile prediction (preevaluation) is also analyzed using a new experiment in which tool wear exists.

The ranges and levels of cutting parameters in new experiment are listed in Table 5. A new training dataset (in Table 6) obtained from the same metrological instrument and experimental setup in Fig. 1 was employed to train a RBF ANN. Similarly, the cutting tool insert was also supposed not to be worn because it was replaced by a new insert once a tool wear defect would appear.

In order to verify the influence of tool wear on the prediction of RBF ANN, a new testing dataset (in Table 7) obtained using a used tool insert with wear defect was used to test the trained RBF ANN. The training of RBF ANN and the decision of the optimal spread value were also conducted using the aforementioned approaches.

A total of $146 \mathrm{RBF}$ network topologies were trained using the training dataset (in Table 6) and 146 different
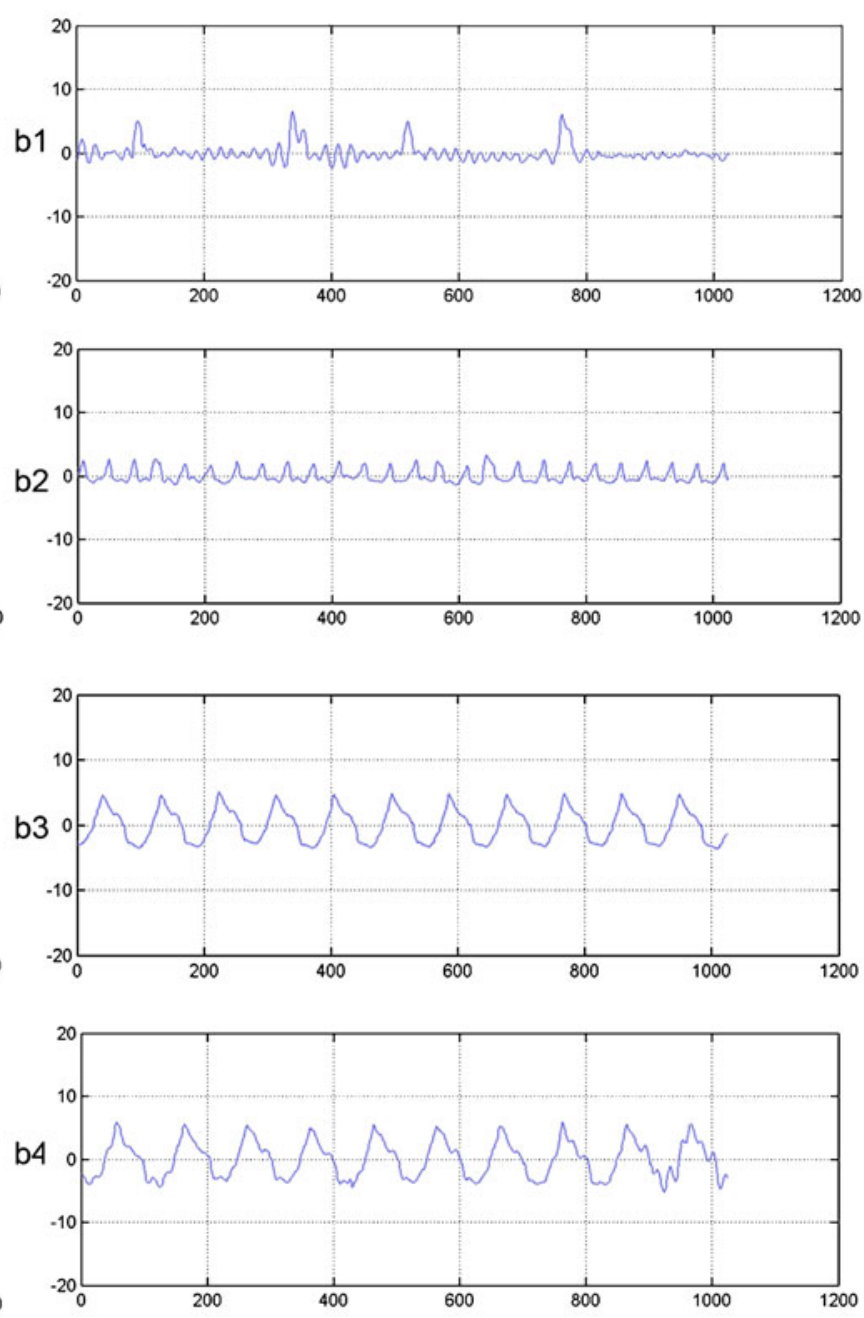

spreads ranging from 0.05 to 1.5 with a step of 0.01 . After evaluating the prediction performance for the given testing dataset in Table 7, it was found that the optimal spread was 0.21 with a MSE of 3.89 .

In Fig. 6, the left subfigures (a1, a2, a3) are "predicted profiles" and the right ones (b1, b2, b3) "measured profiles." The corresponding cutting condition, radius of tool nose, tool materials, and spread are listed as below:

(a1, b1): $v_{\mathrm{c}}=120, a_{\mathrm{p}}=0.45, f=0.05, R_{\mathrm{e}}=0.4$, carbide, spread $=0.21$

Table 8 Testing dataset selected from Table 6

\begin{tabular}{cccccl}
\hline Case no. & $\begin{array}{l}v_{\mathrm{c}} \\
(\mathrm{m} / \mathrm{min})\end{array}$ & $\begin{array}{l}a_{\mathrm{p}} \\
(\mathrm{mm})\end{array}$ & $\begin{array}{l}f \\
(\mathrm{~mm} / \mathrm{rev})\end{array}$ & $\begin{array}{l}R_{\mathrm{e}} \\
(\mathrm{mm})\end{array}$ & $\begin{array}{l}\text { Tool } \\
\text { material }\end{array}$ \\
\hline 1 & 50 & 0.2 & 0.07 & 0.4 & 1 (cermet) \\
2 & 100 & 0.1 & 0.2 & 0.8 & 0 (carb) \\
3 & 400 & 0.4 & 0.07 & 0.4 & 1 (cermet) \\
\hline
\end{tabular}


(a2, b2): $v_{\mathrm{c}}=380, a_{\mathrm{p}}=0.37, f=0.08, R_{\mathrm{e}}=0.4$, carbide, spread $=0.21$

(a3, b3): $v_{\mathrm{c}}=260, a_{\mathrm{p}}=0.2, f=0.18, R_{\mathrm{e}}=0.4$, carbide, spread $=0.21$

(a4, b4): $v_{\mathrm{c}}=220, a_{\mathrm{p}}=0.12, f=0.2, R_{\mathrm{e}}=0.4$, carbide, spread $=0.265$

It is shown from Fig. 6 that the predicted profiles have no good correlation with the measured profiles in terms of profile shape, trend, and amplitude range. The similar prediction results were also obtained for each testing case when some different spreads near 0.21 were tried. The reason that resulted in the significant difference should be the presence of tool wear.

In order to further verify the influence of tool wear, three cases (in Table 8) were selected randomly from Table 6. It has been pointed out that the profile dataset in Table 6 can be supposed not to be worn.

It can be seen from Table 8 that a new group of testing dataset is composed of no. 10 , no. 23 , and no. 58 (in Table 6). The RBF ANNs were trained using the left 61 cases in Table 6. Similarly, for the prediction of surface profile, the same approach was applied to search an optimal spread of newrbe ( ). The optimal spread value was found to be 0.6 at which the corresponding MSE was 4.05. The predicted and measured profiles for the cases in Table 8 are shown in Fig. 7.
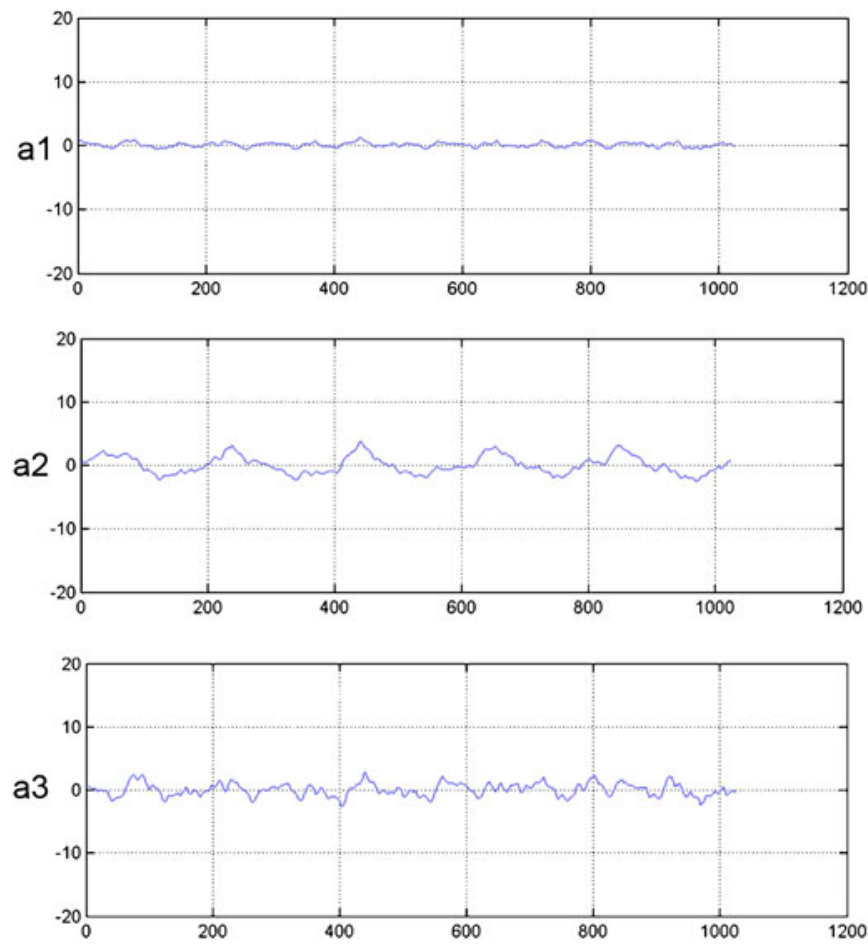

Fig. 7 Comparison between predicted profiles and measured profiles
In Fig. 7, a1, a2, a3 are "predicted profiles", and b1, b2, b3 are "measured profiles," respectively. The corresponding cutting condition, radius of tool nose, tool materials, and spread are listed as below:

(a1, b1): $v_{\mathrm{c}}=50, a_{\mathrm{p}}=0.2, f=0.07, R_{\mathrm{e}}=0.4$, cermet, spread $=0.6$

(a2, b2): $v_{\mathrm{c}}=100, a_{\mathrm{p}}=0.1, f=0.2, R_{\mathrm{e}}=0.8$, carbide, spread $=0.6$

(a3, b3): $v_{\mathrm{c}}=400, a_{\mathrm{p}}=0.4, f=0.07, R_{\mathrm{e}}=0.4$, cermet, spread $=0.6$

It is found in Fig. 7 that the predicted profiles have a good correlation with the measured profiles in terms of profile shape, trend, and amplitude range.

Consequently, it is clear that the proposed approach would give a reasonably accurate prediction (pre-evaluation) on surface profile before machining process in which there is no presence of tool wear (or tool wear can be neglected).

It seems that the prediction of ANN would be more accurate if more in-process factors and features were to be considered and incorporated with ANN prediction models, such as tool wear, vibrations, cutting force, process kinematics, etc. However, considering more in-process factors might result in (1) the cost and complexity of measuring systems would increase; (2) surface quality can only be obtained after machining process; and (3) some complicated mathematic models have to be solved.
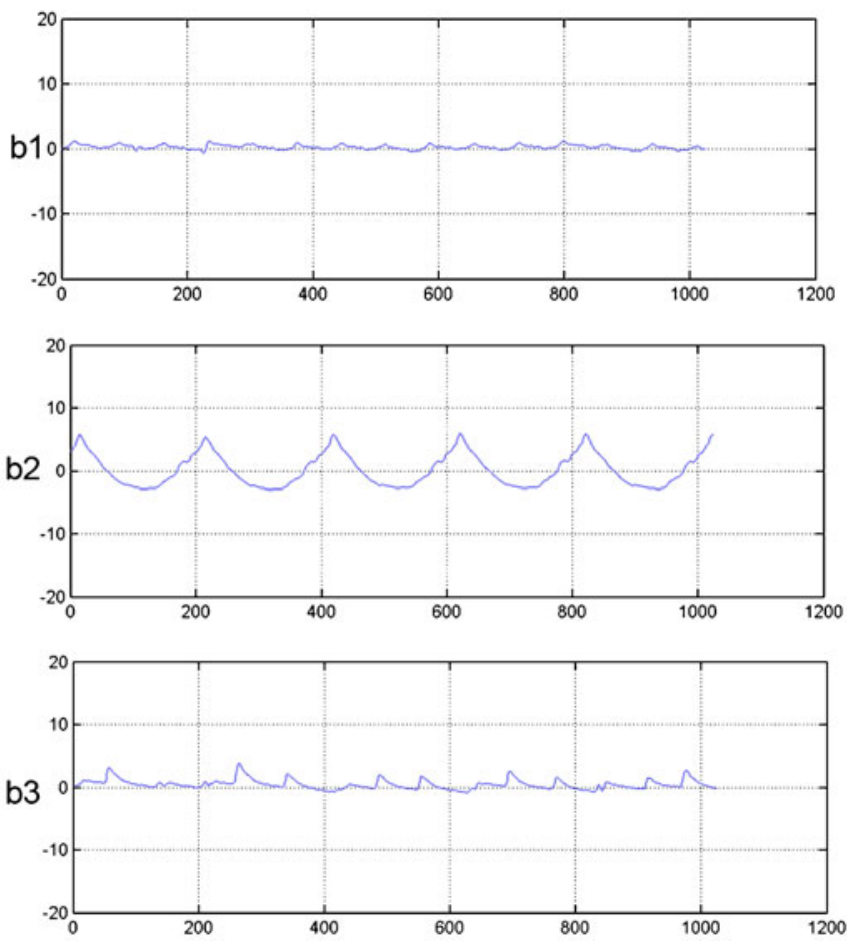


\section{Conclusions and future work}

The conclusions drawn from this paper can be summarized as the following points:

1. The RBF neural network trained by newrbe with adaptive-adjusting spreads for different depths of cut was found to be the optimal network for the prediction (pre-evaluation) of surface profile. The shape, amplitude, and trend of surface profile machined by turning process could be predicted with a good consistency with the actual profile.

2. The developed RBF ANN prediction model using the three cutting parameters $\left(v_{\mathrm{c}}, a_{p}, f\right)$ can realize the prediction (pre-evaluation) of surface profile with high accuracy and low cost before machining process.

3. It should be pointed out that each well-trained RBF prediction (pre-evaluation) model can only correspond to a fixed combination of machining parameters and environment, including cutting parameters $\left(v_{\mathrm{c}}, a_{\mathrm{p}}, f\right)$, tool properties, workpiece properties, machine properties, coolant condition, etc. If the combination is changed, the RBF prediction model should be retrained/readjusted for new pre-evaluation.

4. The proposed approach would give a reasonably accurate prediction (pre-evaluation) on surface profile before machining process in which there is no presence of tool wear (or tool wear can be neglected).

Future work includes:

1. A number of dry and wet turning experiments with HSS, cermet, and carbide-coated tools may be conducted, and RBF ANN prediction models should be established for all these cutting conditions.

2. If not considering the measuring cost and complexity, some features and factors (vibration, displacement, cutting force, kinematics, etc.) could be combined with cutting parameter $\left(\left(v_{\mathrm{c}}, a_{\mathrm{p}}, f\right)\right.$ to online predict surface quality. More ANN input parameters, extracted from sensors of cutting forces, vibrations of spindleworkpiece, displacement signals of tool holder, etc. should theoretically improve the accuracy degree of surface profile prediction after or during machining process. However, the above improvement would increase not only the cost of measuring systems but also the complexity that might import other noises and experimental errors.

3. For in-process or online surface profile prediction, it is difficult to avoid tool wear during turning process; therefore, an effective quantitative representation of tool wear level should be incorporated into prediction models to improve the prediction accuracy.
Acknowledgments This research is supported by the National Natural Science Foundation of China (no. 50705005) as well as by the 863 program of China (no. 2007AA04Z431). The authors are also very grateful to the reviewers and editor for their valuable suggestions on this paper.

\section{References}

1. Benardos PG, Vosniakos GC (2003) Predicting surface roughness in machining: a review. Int J Mach Tools Manuf 43:833-844

2. Grzesik W (1996) A revised model for predicting surface roughness in turning. Wear 194:143-148

3. Chang CK, Lu HS (2006) Study on the prediction model of surface roughness for side milling operations. Int J Adv Manuf Technol 29:867-878

4. Chen C-CA, Liu W-C, Duffie NA (1998) A surface topography model for automated surface finishing. Int $\mathrm{J}$ Mach Tools Manuf 38:543-550

5. Ehmann KF, Hong MS (1994) A generalized model of the surface generation process in metal cutting. CIRP Annal 43:483-486

6. Feng CXJ, Wang X (2002) Development of empirical models for surface roughness prediction in finish turning. Int J Adv Manuf Technol 20:348-356

7. Singh D, Rao PV (2007) A surface roughness prediction model for hard turning process. Int J Adv Manuf Technol 32:1115-1124

8. Lee BY, Tarng YS (2001) Surface roughness inspection by computer vision in turning operations. Int J Mach Tools Manuf 41:1251-1263

9. Tsai DM, Chen JJ, Chert JF (1998) A vision system for surface roughness assessment using neural networks. Int J Adv Manuf Technol 14:412-422

10. Fuchs S (1997) Opportunities of sensor techniques for inspection of wood materials and its impediments. Proceedings of the 13th International Wood Machining Seminar, Vancouver, Canada, pp 289-298

11. Faust TD (1987) Real time measurement of veneer roughness by image analysis. For Prod J 37(6):34-40

12. Mannan MA, Kassim Ashraf A, Ma J (2000) Application of image and sound analysis techniques to monitor the condition of cutting tools. Pattern Recognit Lett 21:969-979

13. Salgado DR, Alonso FJ, Cambero I, Marcelo A (2009) In-process surface roughness prediction system using cutting vibrations in turning. Int J Adv Manuf Technol 43:40-51

14. Liu GJ, Gong YD, Wang WS (2003) On-line measuring of ground surface roughness based on friction-induced acoustic emission. Tribology 23:236-239

15. Diniz AE, Liu JJ, Dornfeld DA (1992) Correlating tool life, tool wear and surface roughness by monitoring acoustic emission in finish turning. Wear 152:395-407

16. Lin SC, Chang MF (1998) A study on the effects of vibrations on the surface finish using a surface topography simulation model for turning. Int J Mach Tools Manuf 38:763-782

17. Jang DY, Choi YG, Kim HG, Hsiao A (1996) Study of the correlation between surface roughness and cutting vibrations to develop an on-line roughness measuring technique in hard turning. Int J Mach Tools Manuf 36:453-464

18. Lou SJ, Chen JC (1999) In-process surface roughness recognition (ISRR) system in end-milling operations. Int $\mathrm{J}$ Adv Manuf Technol 15:200-209

19. Abouelatta OB, Madl J (2001) Surface roughness prediction based on cutting parameters and tool vibrations in turning operations. $\mathrm{J}$ Mater Process Technol 118:269-277 
20. Luo GY, Osypiw D, Irle M (2003) Surface quality monitoring for process control by on-line vibration analysis using an adaptive spline wavelet algorithm. J Sound Vib 263:85-111

21. Risbood KA, Dixit US, Sahasrabudhe AD (2003) Prediction of surface roughness and dimensional deviation by measureing cutting forces and vibrations in turning process. J Mater Process Technol 132:203-214

22. Benardos PG, Vosniakos GC (2002) Prediction of surface roughness in $\mathrm{CNC}$ face milling using neural networks and Taguchi's design of experiments. Robot Comput Integr Manuf $18: 343-354$

23. Ezugwu EO, Fadare DA, Bonney J, Da Silva RB, Sales WF (2005) Modelling the correlation between cutting and process parameters in high-speed machining of inconel 718 alloy using an artifical neural network. Int J Mach Tools Manuf 45:13751385

24. Kohli A, Dixit US (2005) A neural-network-based methodology for the prediction of surface roughness in a turning process. Int $\mathrm{J}$ Adv Manuf Technol 25:118-129

25. Mainsah E, Ndumu DT (1998) Neural network application in surface topography. Int $\mathrm{J}$ Mach Tools Manuf 38(5):591598
26. Abburi NR, Dixit US (2006) A knowledge-based system for the prediction of surface roughness in turning process. Robot Comput Integr Manuf 22:363-372

27. Lela B, Bajié D, Jozié S (2009) Regression analysis, support vector machines, and Bayesian neural network approaches to modeling surface roughness in face milling. Int J Adv Manuf Technol 42:10821088

28. Park J, Sandberg IW (1991) Universal approximation using radial basis functions network. Neural Comput 3:246-257

29. Bi T, Yan Z, Wen F, Ni Y, Shen CM, Wu F, Yang Q (2002) Online fault section estimation in power systems with radial basis function neural network. Electr Power Energy Sys 24:312-328

30. Schalkoff RJ (1997) Artificial neural networks. McGraw-Hill, NewYork

31. Poulachon G, Beaubernard J, Goyet A, Douarche C (1998) Surface roughness modelling by superfinish turning with cutting edge. Proceedings, Volume II of the 2nd International Conference on Integrated Design and Manufacturing in Mechanical Engineering, Compiègne, France, pp 533-540

32. Anonymous (2006) The MathWorks-Online technical documentation. Available via http://www.mathworks.com/access/helpdesk/ help/helpdesk.shtml 